\title{
ANÁLISE DA ESTABILIDADE LATERAL EM TRECHOS FLUVIAIS DA BACIA RIACHO DO TIGRE,
} SEMIÁRIDO PARAIBANO

\author{
Camilla Jerssica da Silva Santos \\ Universidade federal da Paraiba, João Pessoa- PB \\ camilla.jerrsica@hotmail.com \\ Jonas Otaviano Praça de Souza \\ Universidade federal da Paraiba, João Pessoa- PB \\ jonasgeoufpe@yahoo.com.br
}

\begin{abstract}
RESUMO
A pesquisa analisou a estabilidade lateral em ambientes fluviais do Semiárido paraibano na bacia Riacho do Tigre. O foco principal foi estudar a capacidade de ajuste lateral e sua relação com a energia do fluxo, através da identificação da composição do material das margens por meio de teste de textura e consistência, sendo também realizadas análise da cobertura vegetal e da distribuição da energia. Dos oitos trechos avaliados, dois foram classificados como estáveis; quatro, instáveis; e dois com estabilidade intermediária. A partir dos resultados gerados foi possível concluir que a vegetação desempenha um papel fundamental na estabilidade das margens, pois mesmo nas margens compostas de materiais pouco coesos não foram identificados indicios de processos erosivos devido à resistência exercida pela cobertura vegetal.
\end{abstract}

Palavras-chave: Capacidade de ajuste lateral. Energia do fluxo. Resistência de margens.

\section{ANALYSIS OF LATERAL STABILITY OF RIVER STRETCHES IN THE RIACHO DO TIGRE BASIN, PARAIBANO SEMIARID}

\begin{abstract}
The research analysed de lateral stability in Paraiba semiarid fluvials environment at the Tigre stream catchment. The principal objetic was study the capacity of lateral adjusts and his relationship with the margins by texture and consistency tests, being also realized vegetal covers analysis and energy distribution analysis. From the eigth parts evaluated, two of them was classified as steadies; four of them, unsteadies; and two with intermediary stability. From the results was possible conclude that the vegetation develop a fundamental function at the stability of the margins, because even in the poorly bonded composite margins were not identified indications of erosion process caused by the resistence exercised by the vegetal cover.
\end{abstract}

Keywords: Lateral adjust capacity. Flow energy. Bank resistence.

\section{INTRODUÇÃO}

Nos processos de alterações laterais das margens fluviais, os mais recorrentes são as paisagens fluviais e o entendimento do seu mecanismo de atuação é fundamental para a explicação da evolução dos diversos elementos da dinâmica fluvial. Para Hooke (1984), a evolução da migração marginal acontece em curto período de tempo, comparativamente a muitos outros processos geomorfológicos, mostrando assim a importância de conhecimentos sobre a estabilidade lateral dos canais, a fim de possibilitar o planejamento adequado no que concerne ao uso e ocupação das margens. O fenômeno de alargamento e migração dos canais fluviais é facilitado e acompanhado da erosão marginal, que é um processo que ocorre naturalmente em todos os cursos de água. Esse processo resulta do dinamismo natural que caracteriza todos os rios, traduzindo-se numa constante adaptação do rio e numa busca incessante por novos estados de equilíbrio.

Desse modo, os processos físicos e os elementos que controlam a erosão fluvial são essenciais para o entendimento do equilíbrio dos canais, tendo sido abordados em diversos estudos clássicos (Wolman, 1957; Langbein,1968; Knighton, 1973; Hooke, 1979), bem como em estudos

Caminhos de Geografia Uberlândia-MG $\quad$ v. 21, n. 75 Jun/2020 p. 15-33 Página 15


contemporâneos (Stott, 2005; Rinaildi et al, 2008; Acharya e Gautam, 2012; Rocha et al, 2013). Apesar da literatura brasileira registrar poucos trabalhos referentes a esses processos, destacam-se os estudos realizados por Fernandez (1990), Magalhães (2010) e Rocha (2009). Nota-se, porém, que aplicações para ambientes semiáridos e rios intermitentes são ainda mais escassas: Andrade e Cavalcante (2014) traz algumas contribuições para o entendimento da erosão de margens em rios semiáridos, enquanto Andrade (2016) analisa a dinâmica das margens em rios semiáridos.

Nessa perspectiva, o presente trabalho procurou analisar a estabilidade lateral em ambientes fluviais semiáridos, nos canais da bacia do Riacho do Tigre-PB, localizado no Cariri Paraibano (figura 1), tendo como foco principal analisar a capacidade de ajuste lateral e sua relação com a energia dos canais da bacia.

\section{Caracterização da área de estudo}

A bacia em estudo está inserida em um arcabouço de fatores físicos e sociais semelhantes à grande parte do Semiárido nordestino, sendo representativa em relação às bacias de cabeceiras dos maiores rios do Semiárido nordestino. O riacho do Tigre faz parte da drenagem do rio Paraíba, apresentando cerca de $564 \mathrm{~km}^{2}$, estando localizado no município de São João do Tigre (PB), que encontra-se completamente inserido na unidade de relevo do Planalto da Borborema. A parte mais elevada da área de estudo encontra-se na zona dos maciços remobilizados do domínio transversal, enquanto que a parte baixa está situada na depressão intraplanática paraibana (CORRÊA et al, 2010).

Figura 1 - Mapa de localização da Bacia do Riacho do Tigre- PB.

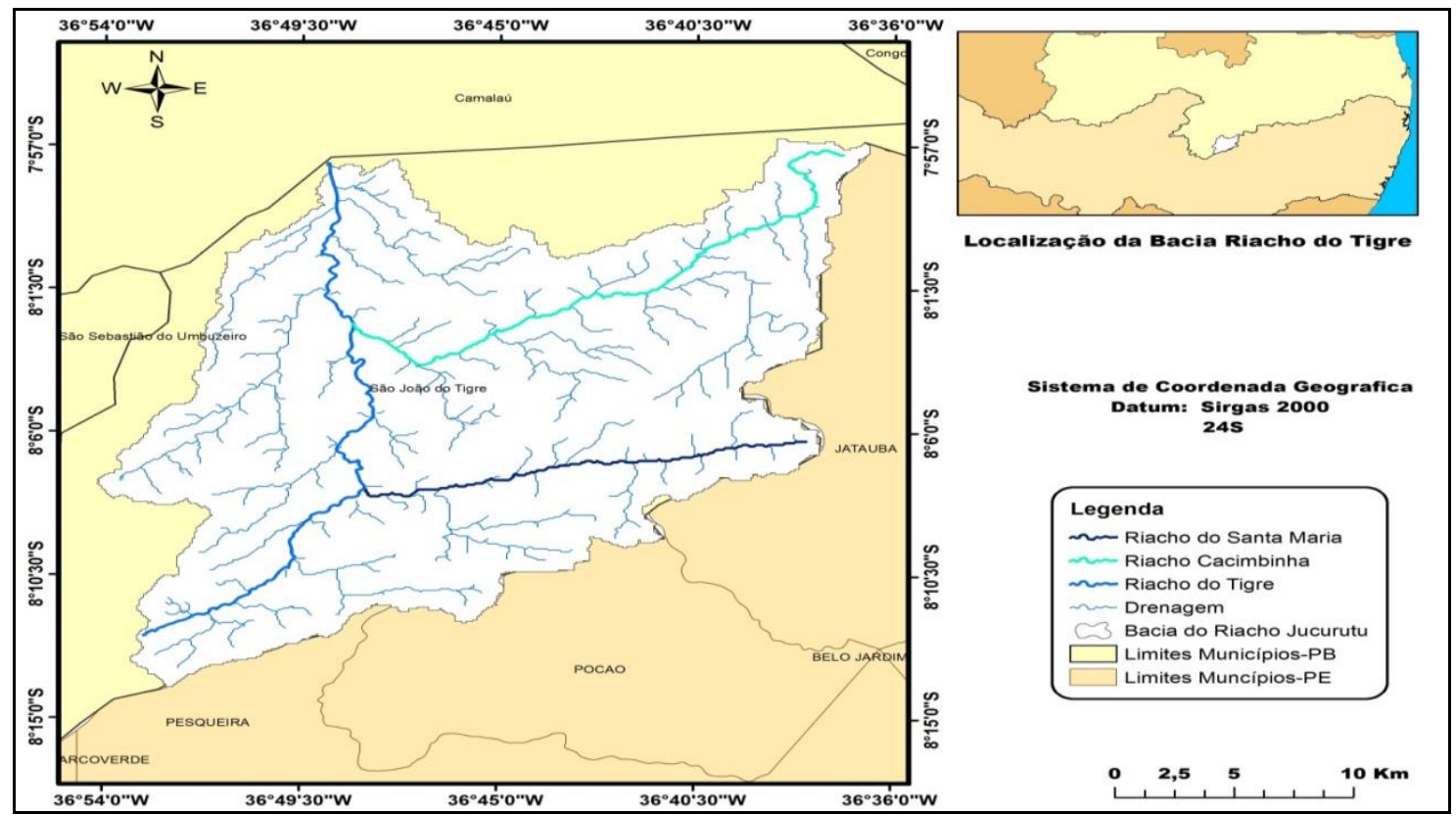

Fonte: Autores, 2016

Além do controle estrutural da área influenciar na disposição dos rios, também irá afetar o clima, reduzindo o grau de temperatura na medida em que a superfície se encontrar mais alta, causando também a diferença de temperatura de vertentes à barlavento e à sotavento.

Portanto, o clima é tropical semiárido, com temperatura média anual de $28^{\circ} \mathrm{C}$. A partir dos índices pluviométricos do posto do São João do Tigre, a média anual é de aproximadamente $431,8 \mathrm{~mm}$ e com um período chuvoso que se estende de janeiro a maio. Desse modo, os rios da bacia são intermitentes, típicos de ambientes semiáridos com ausência de vazão durante a maior parte do ano, apresentando em média 40 dias de fluxo por ano (IBGE,2016). 
No que diz respeito ao uso e cobertura vegetal, a irregularidade pluviométrica, e temperaturas médias e elevadas, acentuando um déficit hídrico na superfície, condicionam a uma configuração fitogeográfica de uma caatinga predominantemente hipoxerófila com presença de alguns trechos de floresta caducifólia (figura 2). Desse modo, é obsevado uma cobertura vegetal basicamente de espécies arbóreas e arbustivas abertas e adaptadas aos períodos de escassez hídrica, algumas espécies fechadas nos ambientes mais altos onde há uma maior presença de umidade.

Figura 2 - Mapa do Uso e Corbetura Vegetal da Bacia do Riacho do Tigre- PB.

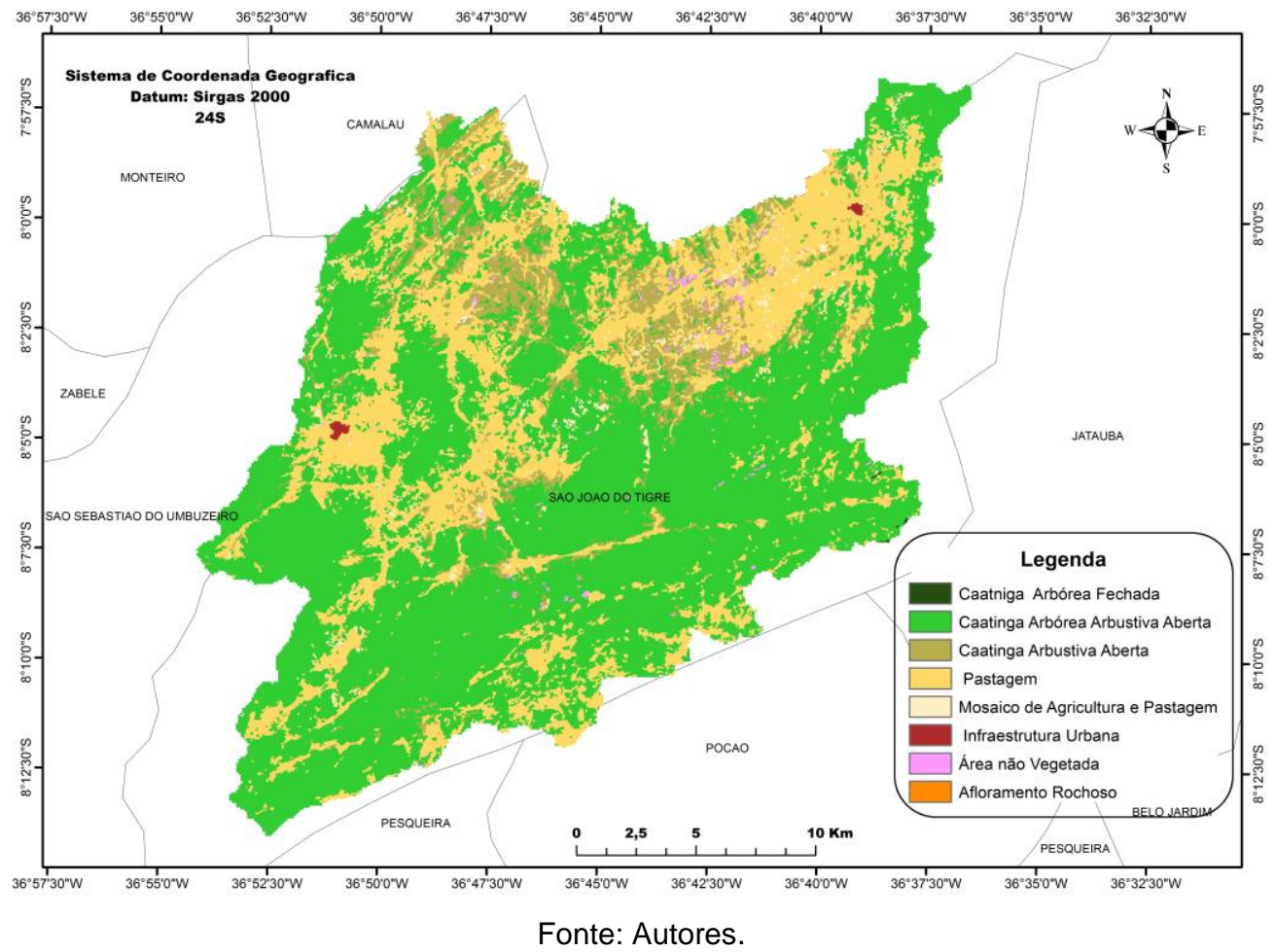

Para análise da estabilidade lateral dos canais, a pesquisa focou em analisar e detalhar trechos representativos da bacia. Por isso vários pontos da bacia foram visitados, sendo escolhidos oito trechos que apresentam características diversas e representativas para demonstrar a diversidade ambiental presente na bacia. Os trechos escolhidos para a análise da estabilidade das margens encontram-se localizados nos três principais riachos da bacia (figura 1): o próprio Riacho do Tigre e seus dois maiores afluentes, o riacho Cacimbinha e o riacho Santa Maria, que apresentam diferentes características e condições de resistência lateral para a estabilidade dos canais.

\section{REFERENCIAL TEÓRICO E METODOLÓGICO}

$\mathrm{Na}$ abordagem sistêmica, os elementos físicos da paisagem estão inter-relacionados como um todo organizado. Mutuamente, a organização está ligada à estabilidade do sistema, pois o padrão de organização gera estabilidade, assim como a estabilidade mantém a organização. Nesta perspectiva, a estabilidade indica a capacidade do sistema, mesmo quando submetido a distúrbios, de manter seu padrão global de organização, seja no mesmo estado em que se encontra antes da perturbação ou em um novo estado. Isso significa que a manutenção da identidade do sistema é dada pelo seu padrão de organização. No entanto, a estabilidade não deve ser entendida como um estado no qual o sistema permanece estático, imóvel, e sim como uma estabilidade relativa e dinâmica. Nesse estado, o sistema está em constante renovação e transformação (MATTOS e PEREZ FILHO, 2004; MORIN, 1977; CHRISTOFOLETTI, 1999).

Para o estudo dos ambientes fluviais é fundamental focar na abordagem sistêmica, realizando uma integração dos diferentes elementos em estudos sobre o ambiente fluvial. Para a análise de forma 
integrada é essencial o recorte espacial, onde a delimitação do sistema é necessária para que se possa analisar a estrutura e comportamento do mesmo. No nosso caso, foi utilizada a bacia hidrográfica. Deve-se ainda avaliar os processos e a estrutura do sistema, levando em consideração tanto os elementos externos à rede de drenagem quanto os elementos presentes na rede de drenagem, além da dinâmica, como os processos sedimentológicos e modificações nos elementos e processos, sendo que o conhecimento das características e dinâmica dos ambientes fluviais é importante para a gestão dos recursos hídricos (BIGARELLA, SUGUIO e BECKER, 1979; SOUZA,2013).

Diante disso, Schumm (1977) coloca a ideia dos domínios processuais dentro de um modelo ideal da bacia hidrográfica, com a possibilidade de compreender as inter-relações dos elementos separados. Dessa maneira, é essencial compreender o comportamento dos rios, o aporte de água e material sedimentar em cada uma das áreas processais, e a quantidade e o tipo de sedimento disponível nessas áreas, além de entender quais são os controles climáticos e geológicos e como eles afetam a dinâmica fluvial, qual o uso do solo e cobertura vegetal e sua relação com as zonas do sistema fluvial, entre outros (COELHO NETTO, 1998; SOUZA e CORREA, 2012).

Um dos elementos que interferem na dinâmica e processos do sistema fluvial é a energia do fluxo. Fryirs e Brierley (2013) explicam que dentro do canal a energia do fluxo é medida como a massa de água que entra no rio a certa altura acima de um determinado nível de base, e como a água se move à jusante, a energia potencial é convertida em energia cinética. Dentro da ideia do modelo ideal da bacia hidrografica, o nível de energia tende a variar, de modo que nas áreas de cabeceira de drenagem o gradiente maior gera maiores potenciais de energia de fluxo. Assim, seguindo em direção à foz a energia do fluxo tende a baixar, visto que o gradiente diminui gradativamente. Ou seja, o gradiente é um dos principais controles da energia do fluxo, em conjunto com o volume de descarga.

Para ambientes fluviais de terras secas, os inputs de energia serão os eventos de precipitação, cujos ambientes se caracterizam por não apresentarem fluxo de água na maior parte do ano. Por isso, a principal característica hidrográfica do ambiente semiárido é o caráter intermitente e efémero dos rios, a descontinuidade dos fluxos. Essa característica está diretamente relacionada com a precipitação na bacia hidrográfica, onde o fluxo de água superficial desaparece durante os longos períodos de estiagem (GRAF, 1988; BIGARELLA, SUGUIO e BECKER, 1979). Desse modo, os processos em ambientes secos, semiáridos e subúmidos apresentam características processuais diferenciadas em relação aos ambientes úmidos, o que irá resultar em diferentes formas e estrutura no sistema (SOUZA e ALMEIDA, 2015).

Para compreensão dessas formas e estruturas em ambientes secos é necessário entender os eventos de cheias, caracterizados por dois extremos hidrológicos: momentos de cheia e momentos de seca. Esses dois eventos de perturbação hidrológica exercem forte influência na organização e no funcionamento dos rios, visto que o padrão para esses ambientes é quando os canais estão secos. Sendo assim, quando o canal apresenta fluxo está no evento de cheia, pois normalmente as respostas de aumento do fluxo nos momentos de precipitações costumam ser mais rápidas do que em regiões úmidas (MALTCHIK, 2012; GRAF, 1988; FRYIRS e BRIERLEY, 2013).

Dentro desse contexto, a organização dos processos fluviais tende à estabilidade, que, como dito anteriormente, apresenta condições que não são rígidas, já que variam de acordo com as características endógenas de cada sistema fluvial, bem como as interferências exógenas. Esses elementos irão gerar diferenciações na capacidade de ajuste lateral e, consequentemente, na morfologia do canal. Contudo, a estabilidade lateral do canal vai depender diretamente de sua resistência, sendo controlada pela composição e disposição do material das margens, assim como na cobertura e uso das mesmas (FRYIRS e BRIERLEY, 2013; MAGALHÃES, 2010).

As propriedades dos materiais são um elemento controlador dos processos erosivos nas margens fluviais, podendo apresentar maior ou menor coesão e, consequentemente, maior ou menor resistência intríseca à erosão, na qual as margens com materiais finos (argilo e silte) tendem a ser coesas por causa das propriedades eletroquímicas das argilas. Já as margens menos estáveis são as do tipo de material mais arenoso, comuns em áreas semiáridas, o que naturalmente contribui para justificar a predominância de canais rasos. As margens rochosas, por sua vez, são comuns em áreas que apresentam um controle litológico no ambiente fluvial, normalmente próximas das cabeceiras, ou em áreas com litologias mais resistentes.

Desse modo, a composição e a forma de crescimento da cobertura vegetal na margem fluvial vão ser essenciais para uma classificação da resistência da mesma, pois as espécies de vegetação 
arbórea/arbustiva densa tendem a apresentar uma maior resistência, enquanto que as áreas antropizadas ou com cobertura vegetal degradada tendem a ser suscetíveis a instabilidades laterais. De uma maneira geral, a consistência do material sedimentar e a cobertura vegetal no ambiente fluvial são os maiores condicionantes da estabilidade fluvial, pois a presença do material de textura coesa nas margens e de uma cobertura vegetal densa conservada manterão diferentes formas e estruturas de organização do ambiente fluvial (NANSON E HICKIN,1986; POLLEN e SIMON, 2005).

Considerando os rios no semiárido, onde ocorre a baixa coesão das margens, uma vez atingido o nível de margens plenas, os processos erosivos podem ser potencializados em questão de dias ou horas, especialmente nas áreas com predomínio de terrenos cristalinos, cujos níveis de água podem ser elevados rapidamente, mediante à intensidade das precipitações. Neste caso, margens desprovidas de vegetação seriam alvos fáceis de desmontes de materiais, provocando de forma rápida o aumento na largura de canais, e, por conseguinte, 0 aumento dos processos de assoreamento. Para a sociedade, isso pode implicar de modo direto no aumento dos riscos de inundações, uma vez que a capacidade de ajuste dos canais podem experimentar rápidas reduções (FRYIRS e BRIERLEY, 2013; CAVALCANTE e CUNHA, 2011).

A energia do fluxo do canal seria o outro elemento-chave de controle para a estabilidade das margens, pois as mudanças dos níveis de fluxo podem refletir a distribuição da energia pelo canal. Isso simboliza que a energia do fluxo estará distribuída pela bacia através da posição do trecho analisado, de modo que nos pontos de maior fluxo e gradiente no canal ela irá atingir níveis mais altos. A variação da energia na bacia irá refletir os diferentes tipos de materiais depositados, incluíndo os depósitos de leito e de margem, influenciando a estabilidade do canal. Dessa forma, qualquer ajuste à distribuição do fluxo de sedimentos ou energia que altere o material - como, por exemplo, os eventos de extrema vazão - pode modificar a estrutura geomorfológica do canal fluvial.

Para Fryirs e Brierley(2013), a energia de fluxo dentro do canal está relacionado diretamente com a massa de água que entra no canal e se move à jusante numa certa altura acima de um determinado nível de base. Portanto, a velocidade das águas dentro do canal fluvial está ligada diretamente ao trabalho realizado pelos rios, ou seja, à erosão, transporte e deposição de sedimentos. Para analisar a importância do trabalho fluvial, deve-se considerar a energia do rio, tanto na sua forma potencial como cinética; dessa forma, a energia potencial é convertida pelo fluxo em energia cinética que, por sua vez, é grandemente dissipada em calor e fricção (CHRISTOFOLETTI,1981; SUGUIO e BIGARELLA, 1990).

\section{MATERIAIS E MÉTODOS}

Para alcançar o objetivo proposto para o estudo, foram estruturados alguns percursos metodológicos, nos quais buscaram-se três fatores essenciais para a análise da estabilização da margem fluvial: materiais que compõem as margens, vegetação associada e a energia do canal.

Inicialmente, foram realizados dois trabalhos de campo exploratórios, com objetivo de fazer o reconhecimento da área da pesquisa, assim como identificar as características ambientais da bacia, a diferença entre os ambientes fluviais e escolher os trechos dos canais que foram analisados. Foram realizados três campos para obtenção de informações necessárias para análise da resistência das margens fluviais, com a finalidade de realizar levantamento e verificação de informações em gabinete, além de esclarecimentos das dúvidas geradas na interpretação dos dados e imagens. No entanto, para realizar os campos de coleta de dados, foi feito um mapeamento prévio através de imagem de satélite, com o intuito de identificar os possíveis trechos fluviais que apresentassem características específicas como cobertura vegetal e variação da textura dos canais dentro do sistema fluvial, que está diretamente relacionada com a resistência.

Desse modo, foram visitados e analisados um total de 36 trechos fluviais nos principais canais da bacia - Riacho do Tigre, Cacimbinha e Santa Maria, e seus afluentes. Para coleta de dados, foi utilizado o GPS topográficos PRO-XH - Trimble, que objetivou a identificação e mapeamento das diferentes classificações de resistências das margens fluviais, assim como também foi utilizada a estação total para elaboração do perfil lateral e longitudinal de todos os trechos fluviais. Entretanto, dos 36 trechos analisados, foram elencados 8 trechos representativos da bacia para analisar $\mathrm{e}$ discutir a estabilidade lateral. 
A identificação da resistência das margens fluvial é um elemento primordial desta pesquisa para poder analisar a estabilidade do canal. Por isso, foram considerados dois fatores essenciais para analisar a resistência das margens fluviais: os materiais que compõem as margens e a vegetação associada.

Sendo assim, nessa identificação foram realizados em campo os testes de consistência e de textura e análise da vegetação associada. Foi feita uma identificação do material constituinte - rochoso ou sedimentar - e, no caso de material sedimentar, foram realizados testes de consistência em diversos pontos da bacia hidrográfica com base no Manual Técnico de Pedologia do IBGE (2007). A textura do material das margens foi exercida com base no diagrama de fluxo para identificação da textura de Thien (1979 apud CAVALCANTI, 2014), que estabeleceu um diagrama de fluxo para identificação da textura através da análise das sensações. Desse modo, a sua identificação é obtida através do umedecimento e modelagem manual de uma amostra de sedimento até formar uma massa homogênea, sem excesso de água. Passada entre os dedos polegar e indicador, esta amostra umedecida pode dar a sensação de aspereza, sedosidade (maciez) ou pegajosidade, que são geralmente associadas à presença de areia, silte e argila, respectivamente.

Em um segundo momento foram analisados a cobertura e o uso associados às margens fluviais. Foram identificadas as formas de crescimento (herbácea, arbustiva e arbórea) e a cobertura vegetal (fechada, aberta e esparsa) a partir da base metodológica de Cavalcanti (2014), aplicadas por meio da visita de campo e também pela análise das imagens de satélite. Sendo assim, as áreas com presenças de espécies arbóreas/arbustivas densas foram classificadas como alta resistência; as áreas com vegetação antropizadas ou com solo exposto, como baixa resistência; e as de espécies arbóreas/arbustivas espaçadas, como média resistência. Para a forma da cobertura vegetal do ambiente ripário, também foram atribuídas classes de resistência: as áreas com densa cobertura vegetal foram classificadas como de alta resistência, já as de cobertura espaçada foram classificadas como média, enquanto os ambientes fluviais cujos canais com presença de planície de inundação apresentam uma vegetação escassa ou degradada foram classificados como margens de baixa resistência.

Após a análise desses fatores essenciais para a resistência lateral do canal, foram elaboradas tabelas com informações da cobertura da vegetação da zona ripária e da textura do material das margens, com o objetivo de compilar informações (tabela 01) e, com isso, chegar a uma classificação de resistência das margens fluviais, classificando-as em alta, média e baixa.

Por meio dessa base de dados, foi identificada e mapeada a resistência das margens para os canais de toda a bacia, com auxílio também de imagens de satélite. A partir da classificação da resistência lateral dos canais fluviais da bacia, foram elencados oito trechos fluviais representativos, que apresentassem diferentes características e condições de resistência lateral e para cada um desses trechos foi realizado o mapeamento fluvial de detalhe com foco no material de composição das margens, acompanhado por uma tabela de informação do material sedimentar, gráficos dos perfis laterais e imagens da área.

Tabela 01 - Matriz de resistência das margens em função da cobertura vegetal do ambiente ripário e composição do material sedimentar das margens.

\begin{tabular}{c|c|c|c}
\hline Material de resistência & Fechada & Intermediaria & Espaçada \\
\hline Rochosa & Alta & Alta & Alta \\
\hline Argilo-siltosa & Alta & Alta \\
\hline Silte & Médio & Médio & Baixo \\
\hline Franco & Médio & Médio & Baixa \\
\hline Franco-argilosa & Médio & Médio & Baixa \\
\hline Franco-argiloarenosa & Médio & Médio & Baixa \\
\hline Areia & Médio & Baixa & \\
\hline
\end{tabular}

Fonte: Autores, 2016. 
Em seguida, foi realizada a identificação da energia total e específica I nos oito trechos analisados, tendo como base Fryirs e Brierley, (2013), onde o total (ou bruto) de energia de fluxo é medido como o volume de água (descarga Q) multiplicado pela declividade do canal s e o peso específico da água, conforme a Eq.1:

$$
\Omega=\gamma \text { Qs } \quad(1) \quad \omega=\Omega / w
$$

Onde $\Omega$ é a o total da energia do fluxo; o $Q$ é a descarga, ou seja, vazão da bacia; s é o gradiente do canal; e y é o valor específico do peso de água, isto é, $9.800 \mathrm{Nm}-2$.

A partir dos valores da energia total, faz-se necessário calcular a energia do fluxo especifico, que consiste no valor da energia total do canal dividida pela largura do canal. Isso representa o trabalho despendido ou a energia gasta pelo canal devido ao regime de fluxo. Desse modo, é medido como potência total de fluxo dividida pela largura do canal, onde $\omega$ é a potência do escoamento específico, $\Omega$ é o fluxo total de energia e W é a superfície da água largura em uma descarga específica.

Com a necessidade de informações da dinâmica de vazão para realização do cálculo da energia total, foi utilizando o modelo hidrossedimentológico geo-espacial ArcSWAT. Como não há dados observados de vazão, não foi realizada a calibração do modelo. Mesmo sem a calibração, os dados se mostram imprescindíveis para a análise inicial sobre os possíveis níveis de descarga da bacia.

Os dados de solo e uso da terra foram disponibilizados pela AESA (Agência Executiva de Gestão das Águas do Estado da Paraíba), enquanto os de precipitação foram concedidos pela ANA (Agência Nacional de Águas). Outros dados climáticos necessários foram os dos parâmetros climáticos (temperatura, precipitação, velocidade do vento, radiação solar e de umidade relativa do ar), baseados em Carvalho Neto (2011). O autor aplicou o modelo SWAT para a bacia experimental de São João do Cariri, localizada no estado da Paraíba, para analisar a influência das mudanças no uso do solo no comportamento da produção de sedimentos e do escoamento superficial, utilizando a base da estação climática presente na Bacia Escola. Essa bacia hidrográfica experimental é encontrada nas coordenadas 7²2'45,1"S e 36ำ31'47,2"W e está localizada no município de São João do Cariri PB, com altitude de $458 \mathrm{~m}$, apresentando uma distância de $83 \mathrm{~km}$ da bacia Riacho do Tigre.

A opção por esses dados se deve ao fato da estação climática apresentar dados representativos para as características climáticas de toda a região, incluindo a área da bacia riacho do Tigre. Por fim, os dados de declividade foram obtidos a partir do processamento de imagens SRTM (Shuttle Radar Topography Mission), obtidas pela plataforma de dados online Brasil em Relevo, organizada e classificada pela EMBRAPA.

Finalmente, para a obtenção dos valores de vazão em cada trecho analisado, através do modelo hidrossedimentológico, foram calculadas a energia média, máxima e especifica do fluxo para os oitos trechos fluviais representativos da bacia. Além disso, o gradiente do canal foi medido em campo utilizando estação total e, para uma melhor percepção da posição na bacia de cada trecho, foi calculada a área de captação de cada um deles.

\section{RESULTADOS E DISCUSSÕES}

A análise da estabilidade desses trechos será dividida em duas partes. Inicialmente, será avaliada a resistência e, posteriormente, irá se relacionar a resistência com a energia do fluxo nos trechos, identificando assim o potencial de estabilidade lateral deles.

Tendo identificado e espacializado as informações de resistência dos canais da Bacia (figura 3) para os trechos fluviais que estão classificados com resistência alta, apresenta-se como fator primordial as margens compostas de material rochoso ou margens com material argiloso associado à cobertura vegetal densa. Desse modo, os canais que apresentam essas características estão predominantemente localizados nas áreas serranas da Bacia, que apresenta maior predomínio de canais rochosos. 
Figura 3 - Mapa de resistência dos canais da Bacia Riacho do Tigre - PB.

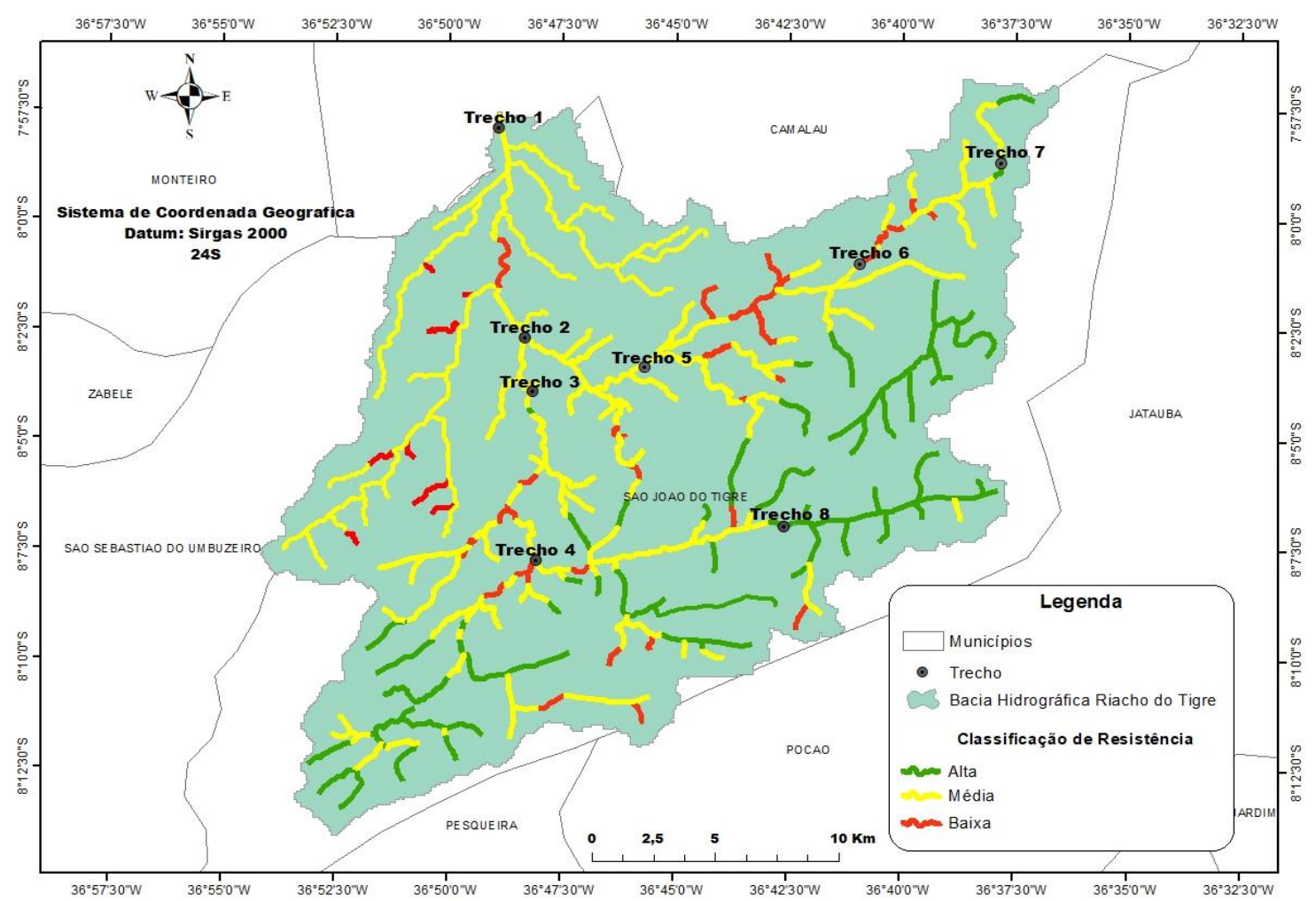

Fonte: Autores, 2016.

Já os canais de resistência média apresentam margens com textura franca-argilosa, franca-siltosa ou franca-arenosa que, apesar da baixa coesividade do material, demonstram a presença de cobertura vegetal densa, contribuindo na resistência à erosão e, com isso, mantendo um nível mediano de resistência. Por fim, os trechos classificados como baixa resistência caracterizam-se pelas margens compostas de material pouco coeso, como os de textura arenosa, franco ou areia-franca, relacionados a uma cobertura vegetal espaçada ou degradada. Assim, as áreas de média e baixa resistência lateral dos canais estão localizadas nas partes baixa do relevo, nas áreas semiáridas. Por isso, de todos os trechos fluviais onde foi mapeada a resistência lateral dos canais, foram escolhidos 8 trechos representativos, com a finalidade de detalhar os elementos e processos que estão influenciando na resistência das margens.

\section{Análise dos Trechos Fluviais de Alta Resistência Lateral}

Os trechos 7 e 8 foram classificados como sendo de alta resistência lateral, por se caracterizarem como canais confinados, cuja classificação e caracterização dos vales foi realizada por Brierley \& Frirys (2005), que afirmam que o vale se configura sem a presença de planícies de inundação, não ocorrendo assim o extravasamento do fluxo. Ambas as margens e leitos são rochosos, apresentando blocos soltos e lâminas de areias em pontos isolados, com potenciais a ajustes limitados ou inexistentes. Além disso, os trechos apresentam margens íngremes, bem características de canais encaixados em falhas. Ambos apresentam morfologia irregular do leito e das margens, que é imposta pela irregularidade dos afloramentos rochosos e pela presença de grandes blocos.

Porém, em relação à variável da cobertura vegetal associada às margens no trecho 7 , localizada na cabeceira do riacho Cacimbinha (figura 4), vê-se vegetação degradada com a predominância de herbáceas, assim como a presença esparsa de espécies arbustivas e de indivíduos arbóreos isolados. Apesar da falta de proteção vegetal, a composição rochosa das margens controla a resistência lateral, sendo definida como alta resistência, com baixa capacidade de ajuste a mudanças nos fluxos. No perfil lateral, pode-se observar a configuração do vale estreito, com uma forma irregular. Isto indica que a morfologia foi imposta devido à presença dos blocos rochosos. 
O trecho 8 , situado no riacho Santa Maria, foi identificado com alta resistência lateral, não só pelo fator da resistência do material das margens, cuja rochosidade é o fator controlador, mas também pela predominância da vegetação arbórea-arbustiva densa associada às margens. Além da alta declividade nas encostas, como pode ser observado no perfil lateral na figura 5 , a alta densidade da vegetação não permitiu pegar pontos na encosta do lado esquerdo e, por isso, não é possível visualizar a encosta da margem esquerda, tendo dessa forma a vegetação como indicador de alta resistência para as margens, além do próprio material das margens.

Figura 4 - Representa o mapa de uso/ cobertura do Trecho 7. A) O perfil lateral do canal, onde a sua localização está sendo representada no mapa de uso e cobertura. B) Imagem do trecho analisado. Data: 04/2016.

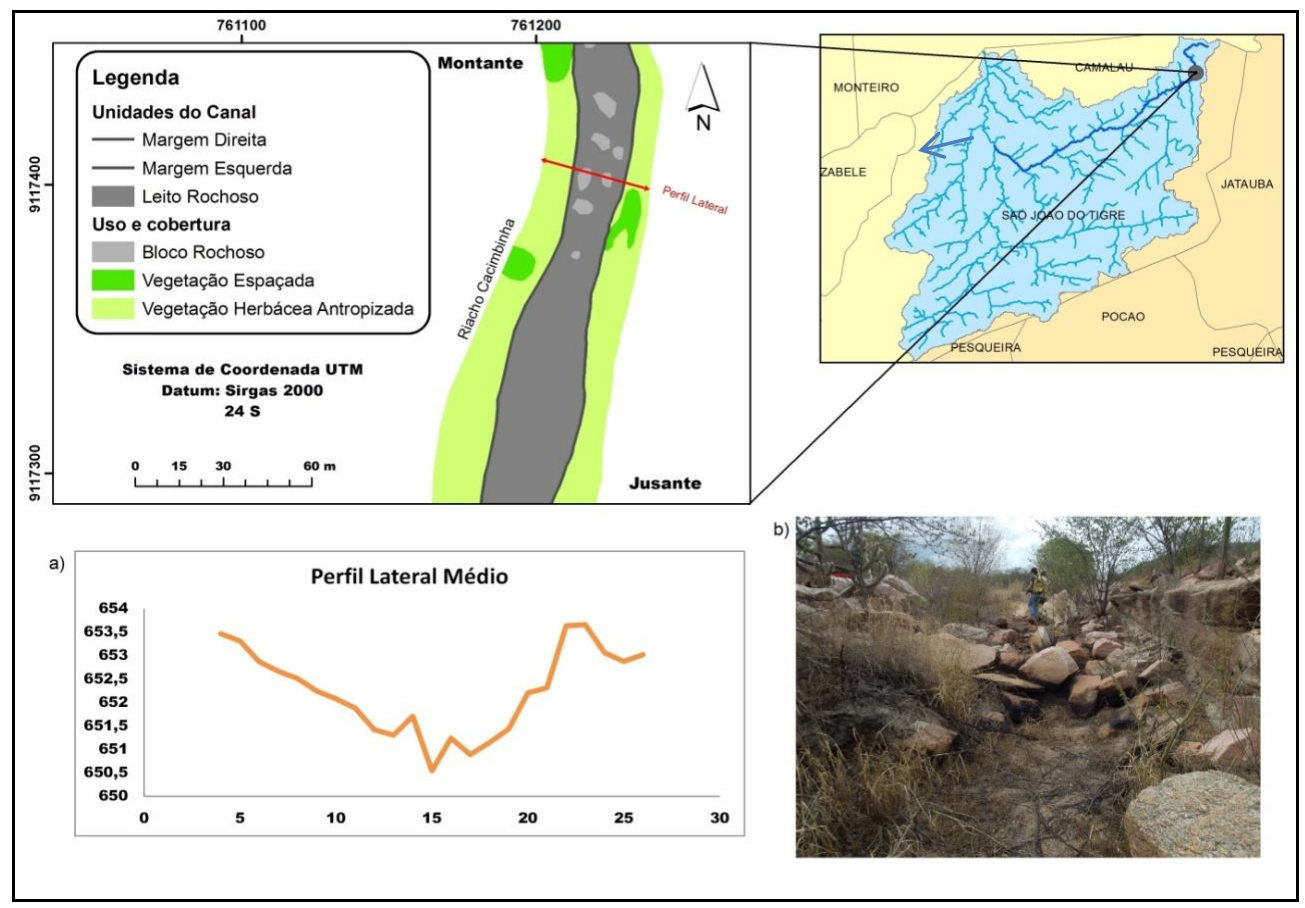

Figura 5 - Mapa de uso/ cobertura do Trecho 8. A) O perfil lateral do canal, no qual a sua localização está sendo representada no mapa de uso e cobertura. B) Imagem do trecho analisado. Data: 02/2016.

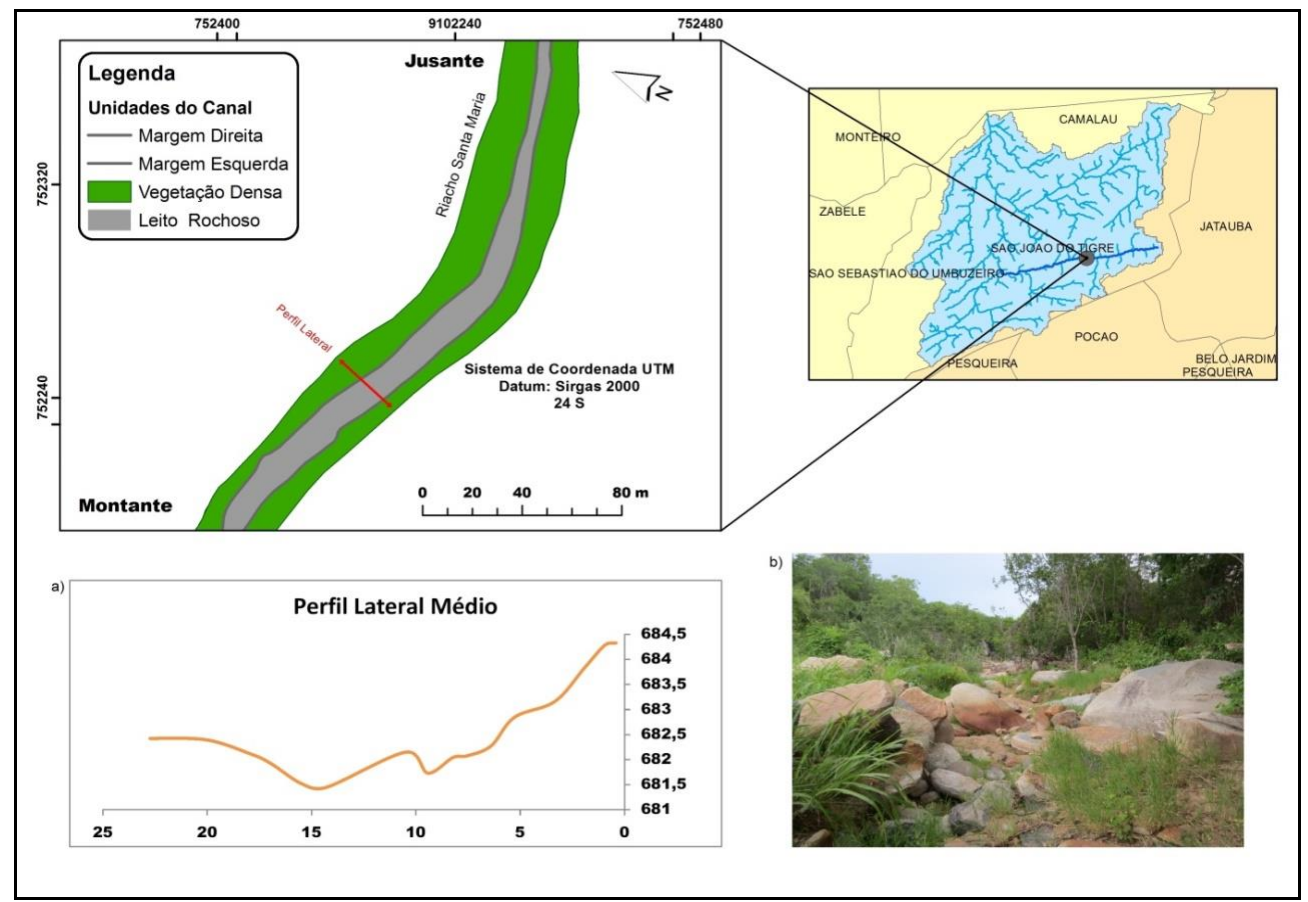

Fonte: Autores, 2016. 


\section{Análise dos Trechos Fluviais de Resistência Lateral Média}

A resistência lateral mediana predomina na Bacia e, por isso, foram elencados quatro diferentes trechos para detalhamento. Apesar de todos apresentarem um nível médio de resistência, eles mostram diferentes arranjos nos fatores controladores da resistência lateral do canal, sendo uma amostra representativa para a diversidade das áreas com resistência média.

O trecho 1, classificado com resistência média, está localizado na foz da bacia hidrográfica e, de modo geral, apresenta características típicas deste ambiente fluvial. Esse trecho revela configuração de vale não confinado que, ao contrário do confinado, se caracteriza pela ocorrência do extravasamento do fluxo em ambas as margens fluviais, isto é, terá planície de inundação em ambas as margens, o que indica maior capacidade de ajuste do canal e instabilidade das margens devido à ausência de controles litológicos (Brierley \& Frirys, 2005). O leito apresenta textura arenosa, comuns em ambientes fluviais do semiárido com predominância de transporte por carga de fundo. Como pode ser observando no perfil lateral, o trecho apresenta o vale largo com uma divisão do canal por uma barra arenosa (figura 6).

Analisando o material das margens, observou-se que a margem esquerda tem textura arenosa e a direita, argilo-siltosa. Com base na tabela de grau de textura de Friyis \& Brierley (2013), o material sedimentar apresenta em média $25 \%$ de silte e 30\% a $40 \%$ de argila. Então, ao contrário da margem esquerda, esse apresenta ligeira pegajosidade e plasticidade, fatores que contribuem para a resistência. Já a cobertura de ambas as margens fluviais apresenta espécies da caatinga herbácea e arbustiva com cobertura densa. Sendo assim, mesmo tendo alguma parte de solo exposto e intervenções antrópicas, não apresentam sinais erosivos, sendo classificadas como de resistência média, devido principalmente à alta densidade da vegetação associada às margens.

Figura 6 - Mapa de uso/cobertura do Trecho 1. A) O perfil lateral do canal, cuja localização está sendo representada no mapa de uso e cobertura. B) Imagem do trecho analisado. Data: 02/2016. A tabela 01 representa as informações de textura e consistência do material sedimentar identificadas nas margens do trecho 1

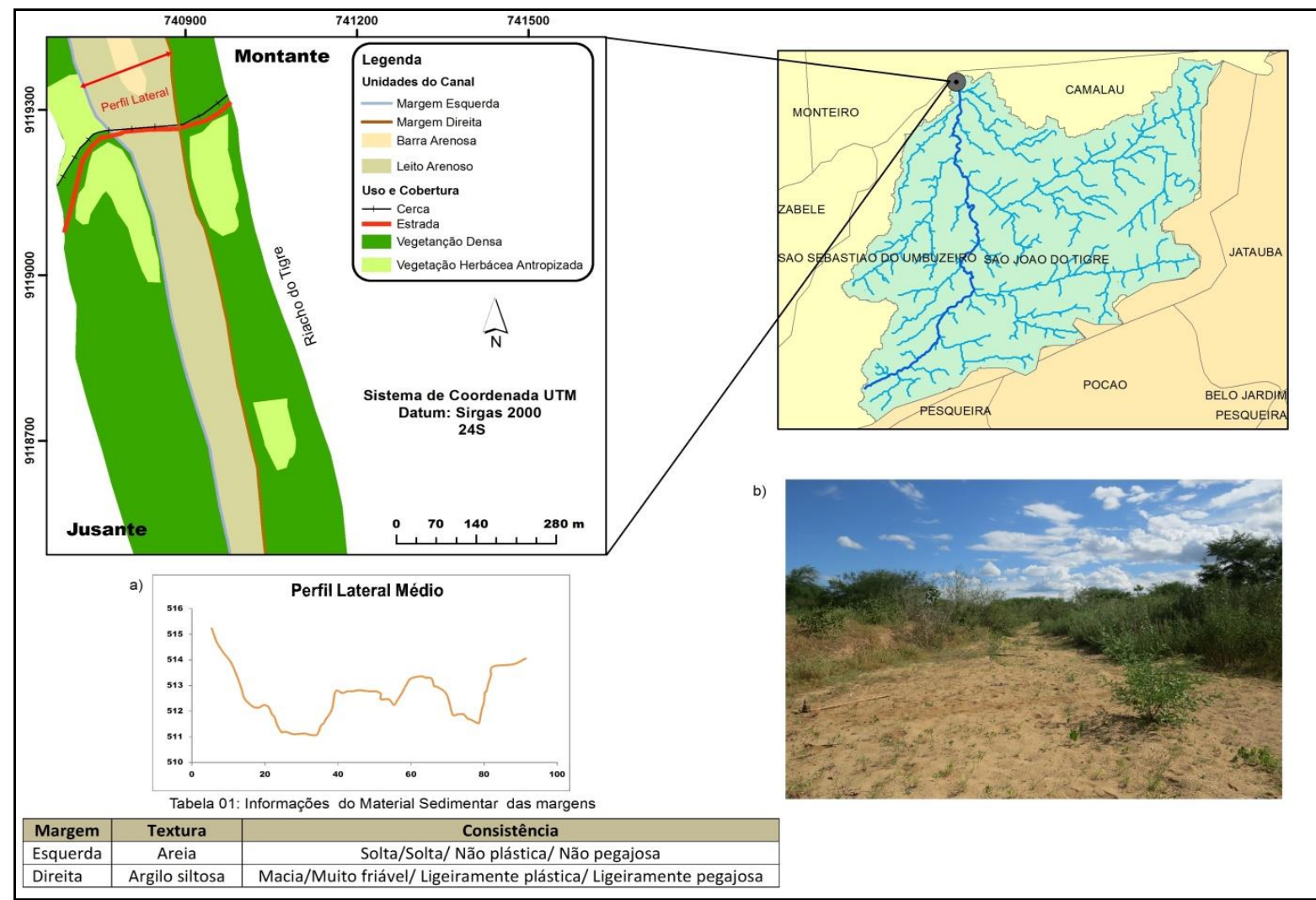

Fonte: Autores, 2016 
No trecho 2, localizado na confluência entre o riacho do Tigre e o riacho Cacimbinha, foi encontrado um material muito resistente que apresenta uma alta coesão devido a teores maiores de argila no material da margem. Assim, na margem esquerda do Riacho Cacimbinha foi identificada uma textura argilo-siltosa, que frações da granulometria apresentam em média $25 \%$ de silte e $30 \%$ a $40 \%$ de argila, enquanto na margem direita a textura é argilosa. Já na margem esquerda do riacho do Tigre, vê-se uma textura argilo-siltosa e na margem direita, uma textura franco-argilosa, que em média apresenta $25 \%$ de silte e $30 \%$ a $40 \%$ argila.

Ao avaliar a vegetação associada, observa-se o uso agrícola das margens, onde não há basicamente presença de vegetação permanente, estando a vegetação existente em estágio avançado de degradação. Como consequência, o fator de proteção do impacto da chuva contra o solo e a função das raízes na coesão dos materiais da margem são diminuídos.

O trecho na variável de análise da vegetação se apresenta como trecho mais antropizado da bacia, porém, devido a composição do material ser coesa, este trecho não foi classificado como baixa resistência e sim como média. Isso significa que, apesar da degradação da vegetação, a resistência interna do material superficial controla a resistência à erosão, tendo uma resistência média inclusive em eventos chuvosos fortes e algumas horas após esses eventos, quando as vazões atingem seus picos e a energia do fluxo se encontra alta. No perfil lateral médio (figura 7), onde há uma visualização do corte lateral do canal, pode-se observar a forma irregular no canal do riacho do Tigre e no canal do riacho Cacimbinha e que as margens apresentam uma forma mais vertical com algumas irregularidades.

Figura 7 - Mapa de uso/ cobertura do Trecho 2. A) O perfil lateral do canal, no qual a sua localização está sendo representada no mapa de uso e cobertura. B) Imagem do trecho analisado. Data: 02/2016. A tabela 01 representa as informações de textura e consistência do material sedimentar identificados nas margens do trecho 2.

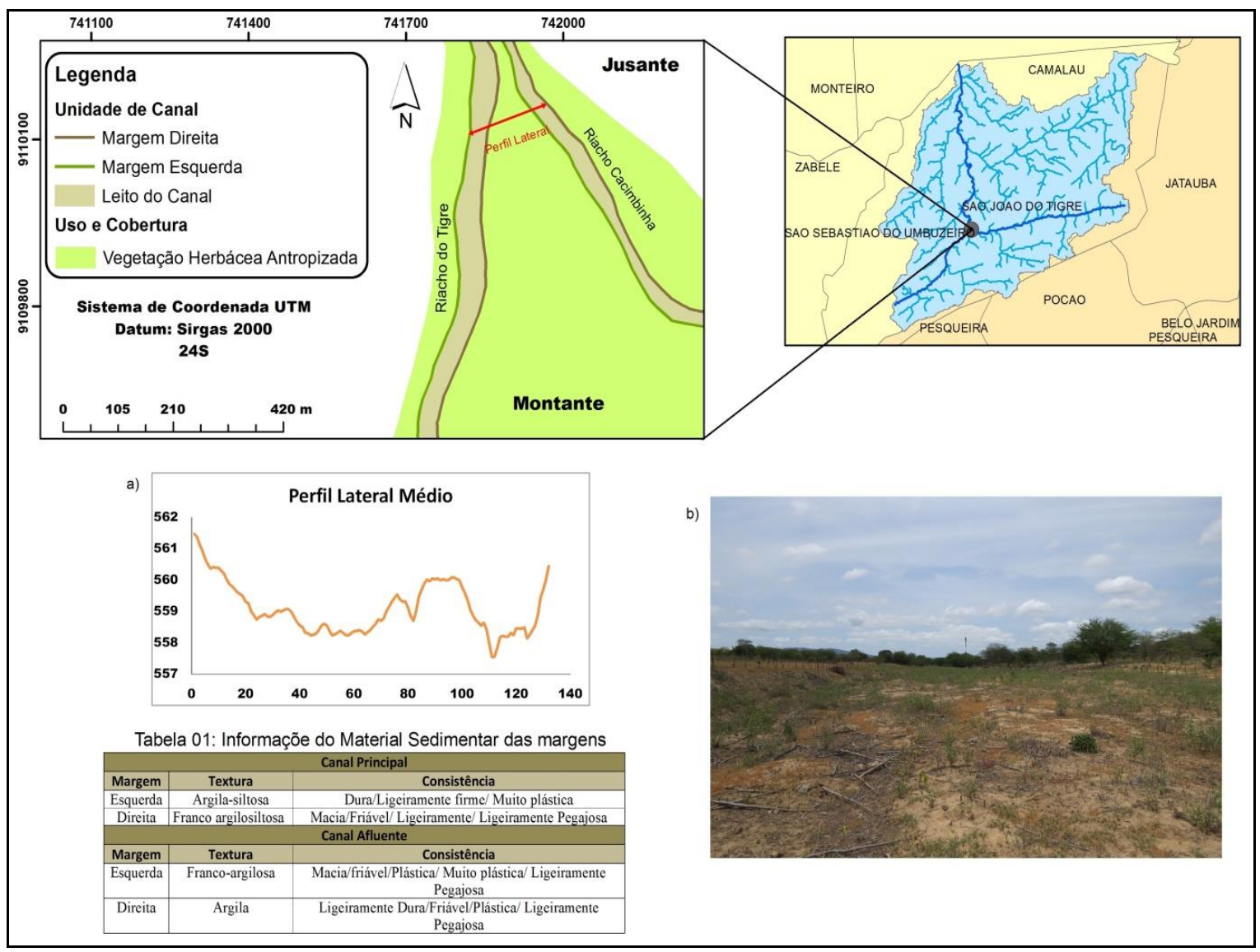

Fonte: Autores, 2016. 
Ainda no percurso do riacho do Tigre, à jusante do trecho anterior, o trecho 3 foi escolhido para ser analisado por apresentar uma textura arenosa tanto do leito quanto das margens, que contribui para o canal apresentar forma sinuosa, com margens caracterizadas por formas assimétricas. Ao contrário do trecho anterior, este apresentou uma cobertura vegetal densa e o material das margens é não coeso (figura 8). Na margem esquerda, os testes de consistências apresentaram um material solto, não plástico e muito friável, sendo identificado como textura de areia. Já na margem esquerda, a consistência apresentou características macias, plásticas e muito friáveis, sendo identificada como franco-argilosiltosa, cujas frações granulométricas são representadas em média por $25 \%$ de silte e $30 \%$ a $40 \%$ de argila. Desse modo, por apresentar uma porcentagem baixa de frações granulométricas de silte e argila, é um material que não apresentam coesão, o que torna esse trecho menos resistente à erosão e mais suscetível a modificações na morfologia, como pode-se observar na sinuosidade do referido canal.

Figura 8 - Mapa de uso/ cobertura do Trecho 3. A) O perfil lateral do canal, no qual a sua localização está sendo representada no mapa de uso e cobertura. B) Imagem do trecho analisado. Data: 02/2016. A tabela 01 representa as informações de textura e consistência do material sedimentar identificados nas margens do trecho 3.

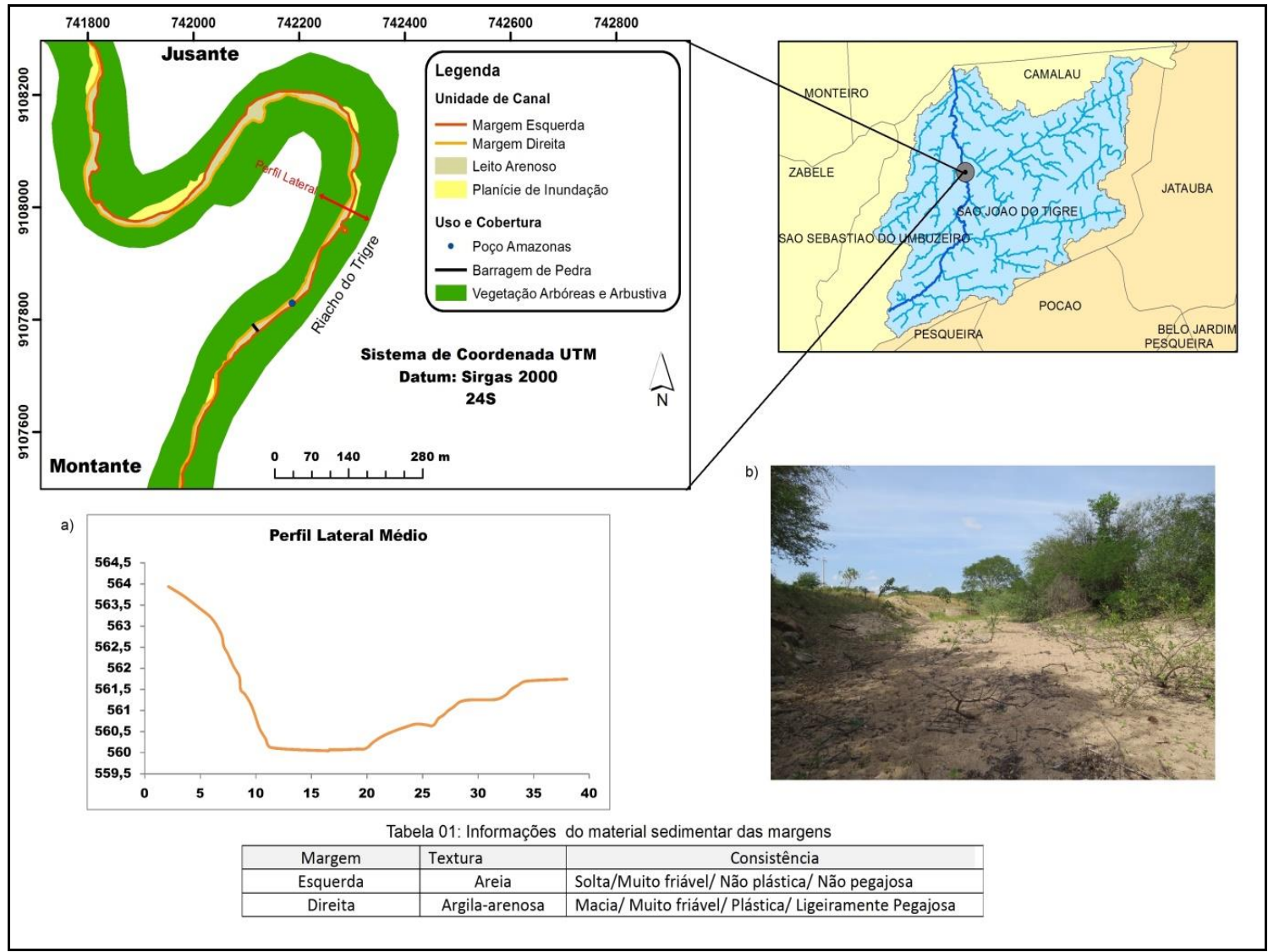

Fonte: Autores, 2016.

Apesar da baixa coesividade do material das margens, o trecho foi classificado com de resistência média, pois apresenta espécies arbóreas e arbustivas com predominância de vegetação arbustiva de cobertura densa. Desse modo, a vegetação aumenta a estabilidade das margens criando uma estrutura de raízes que apresentam uma elevada resistência e reduzindo a velocidade da água junto à margem no período de alta vazão.

Por fim, o trecho 5, localizado no riacho Cacimbinha, também foi classificado como média resistência nas margens, podendo-se afirmar que o material que compõe as margens é o fator controlador da resistência. Localizado à montante da confluência do Riacho Cacimbinha, se caracteriza por possuir leito arenoso e uma cobertura vegetal com predominância de espécies de arbustiva densa em ambas as margens (figura 9). 
Em relação ao material que compõe as margens, foi identificado textura franca, na qual as frações granulométricas são representadas em proporções de partículas de areia, silte e argila. No entanto, as quantidades não foram exatamente iguais, visto que uma porcentagem relativamente pequena de argila é suficiente para influenciar no material sedimentar, considerando que pequenas quantidades de areia e silte possuem menor influência sobre o comportamento do material sedimentar. Dessa forma, ambos os elementos, material e vegetação, indicaram uma resistência média para a área.

Figura 9 - Mapa de uso/ cobertura do Trecho 5. A) O perfil lateral do canal, no qual a sua localização está sendo representada no mapa de uso e cobertura. B) Imagem do trecho analisado. Data: 04/2016. A tabela 01 representa as informações de textura e consistência do material sedimentar identificados nas margens do trecho 5.

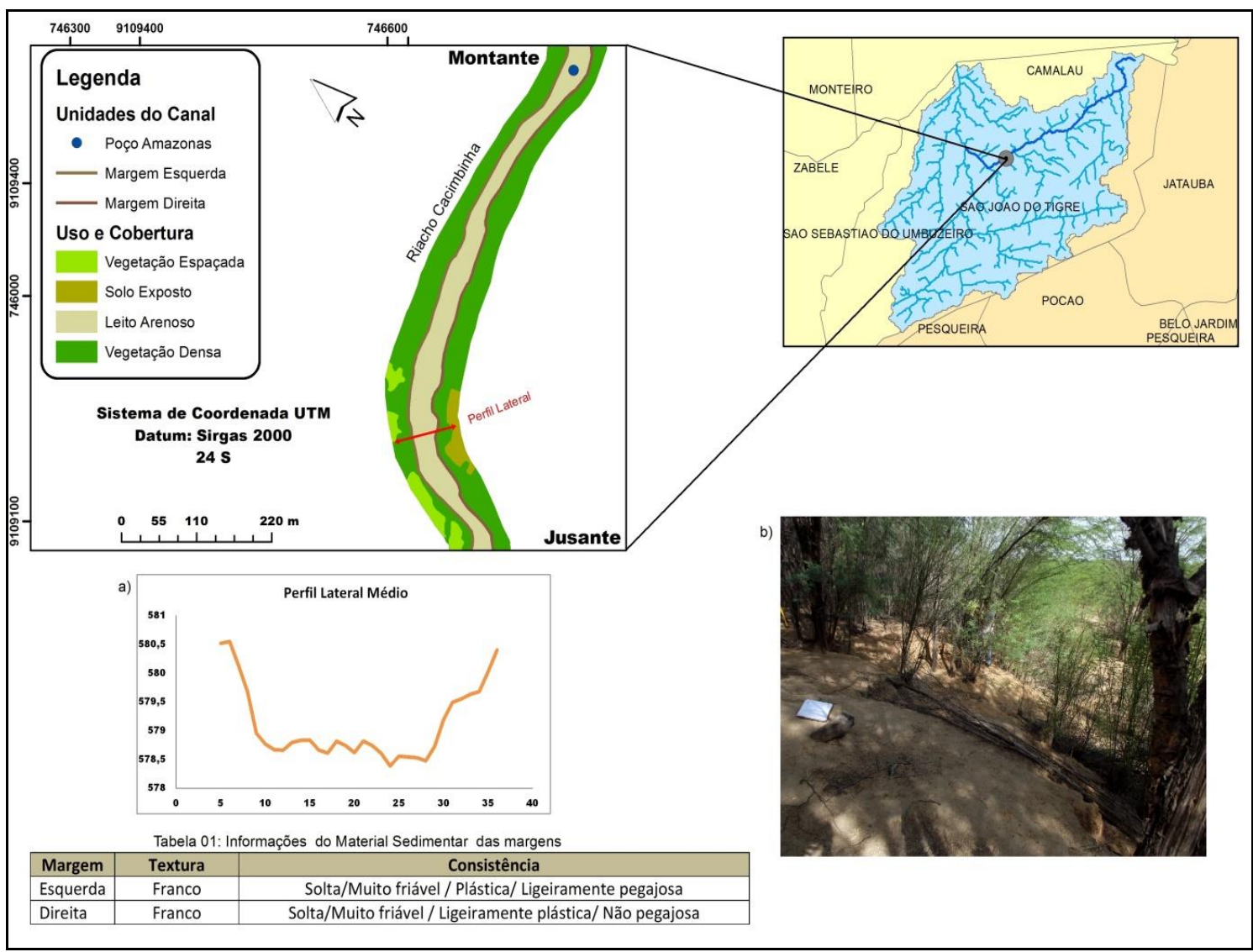

Fonte: Autores, 2016.

\section{Análise dos Trechos Fluvial de Baixa Resistência Lateral}

Para representar as configurações de baixa resistência lateral, foram selecionados dois trechos em que a visível erosão nas margens explicitou a caracterização de baixa resistência. $O$ trecho 4 , classificado como de baixa resistência, está localizado na confluência entre o Riacho do Tigre e o Riacho Santa Maria, e apresenta leito arenoso com presença de pedregosidade. Além disso, a forma do vale está caracterizada como irregular, principalmente nas margens cuja planície de inundação divide os canais (figura 10).

Para o Riacho do Tigre, a margem esquerda apresentou material sedimentar de textura francoargilosa, na qual há uma predominância de frações granulométricas de argila, mas não o suficiente para o material apresentar uma consistência plástica e pegajosa. Por sua vez, a margem direita possui textura de areia franca, também caracterizada por ter a predominância de material de baixa coesão, já que não apresenta uma consistência nem plástica e nem pegajosa. Ao mesmo tempo, a vegetação associada às margens apresenta-se degradada e espaçada, não auxiliando na resistência lateral que, pela relação de material de baixa resistência e vegetação degradada, foi classificada como área de baixa resistência. 
No caso do Riacho Santa Maria, apesar das margens serem compostas por material similar, a predominância de vegetação densa e a baixa intervenção antrópica colocaram a área na classificação de média resistência. Esse cenário demonstra a importância da cobertura vegetal associada às margens para classificar a resistência nos processos de migração e erosão lateral dos ambientes fluviais.

Figura 10 - Mapa de uso/ cobertura do trecho 4. A) O perfil lateral do canal, cuja localização está sendo representada no mapa de uso e cobertura. B) Imagem do trecho analisado. Data: 02/2016. A tabela 01 representa as informações de textura e consistência do material sedimentar identificados nas margens do trecho 4.

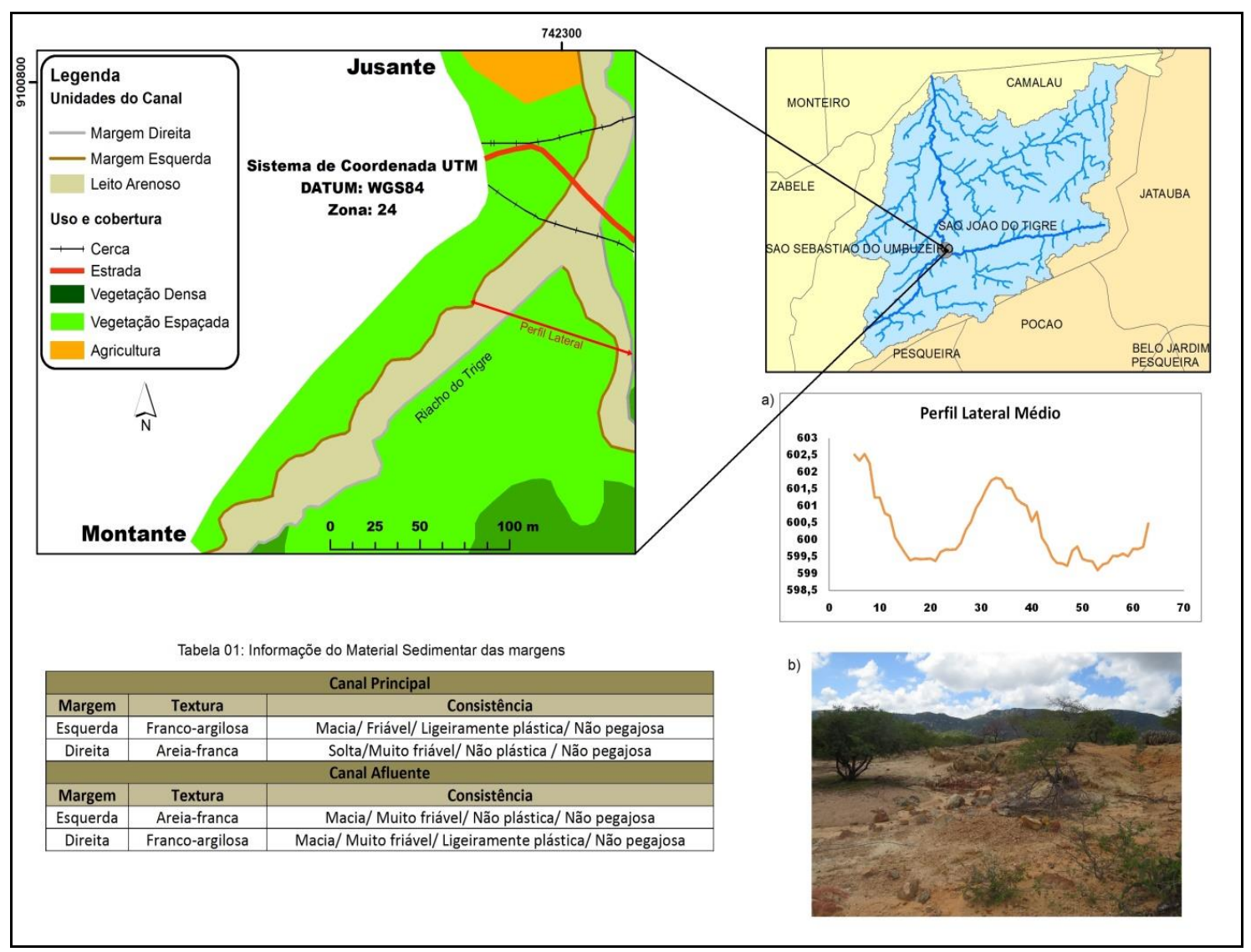

Fonte: Autores, 2016.

Por fim, o trecho 6 apresentou uma baixa resistência das margens, também tendo como características leito arenoso com um canal de forma similar aos canais simétricos, contudo apresentando variações relacionadas ao nível de inundação, mostrando assim processos erosivos nas margens.

Desse modo, observa-se linhas erosivas nas margens, principalmente na margem direita, onde são áreas de baixa resistência lateral, compostas de material siltoso, não apresentando alta coesão, caracterizado assim por não apresentar plasticidade e pegajosidade.

Já na margem esquerda, foi identificada uma textura de areia franca. Ao mesmo tempo, apesar de apresentar vegetação arbórea e arbustiva, a cobertura é espaçada, caracterizando-se como cobertura degradada. Desse modo, relacionando-se a baixa proteção da vegetação com a baixa coesão do material das margens, esse trecho foi classificado tendo baixa resistência lateral. A variação da vegetação - de espécies arbóreas e arbustiva - entre os trechos foi caracterizada por uma cobertura espaçada, com predominância do solo exposto (figura 11). 
Figura 11 - Mapa de uso/ cobertura d/o trecho 6. A) O perfil lateral do canal, no qual a sua localização está sendo representada no mapa de uso e cobertura. B) Imagem do trecho analisado. Data: 04/2016. A tabela 01 representa as informações de textura e consistência do material sedimentar identificados nas margens do trecho 6 .

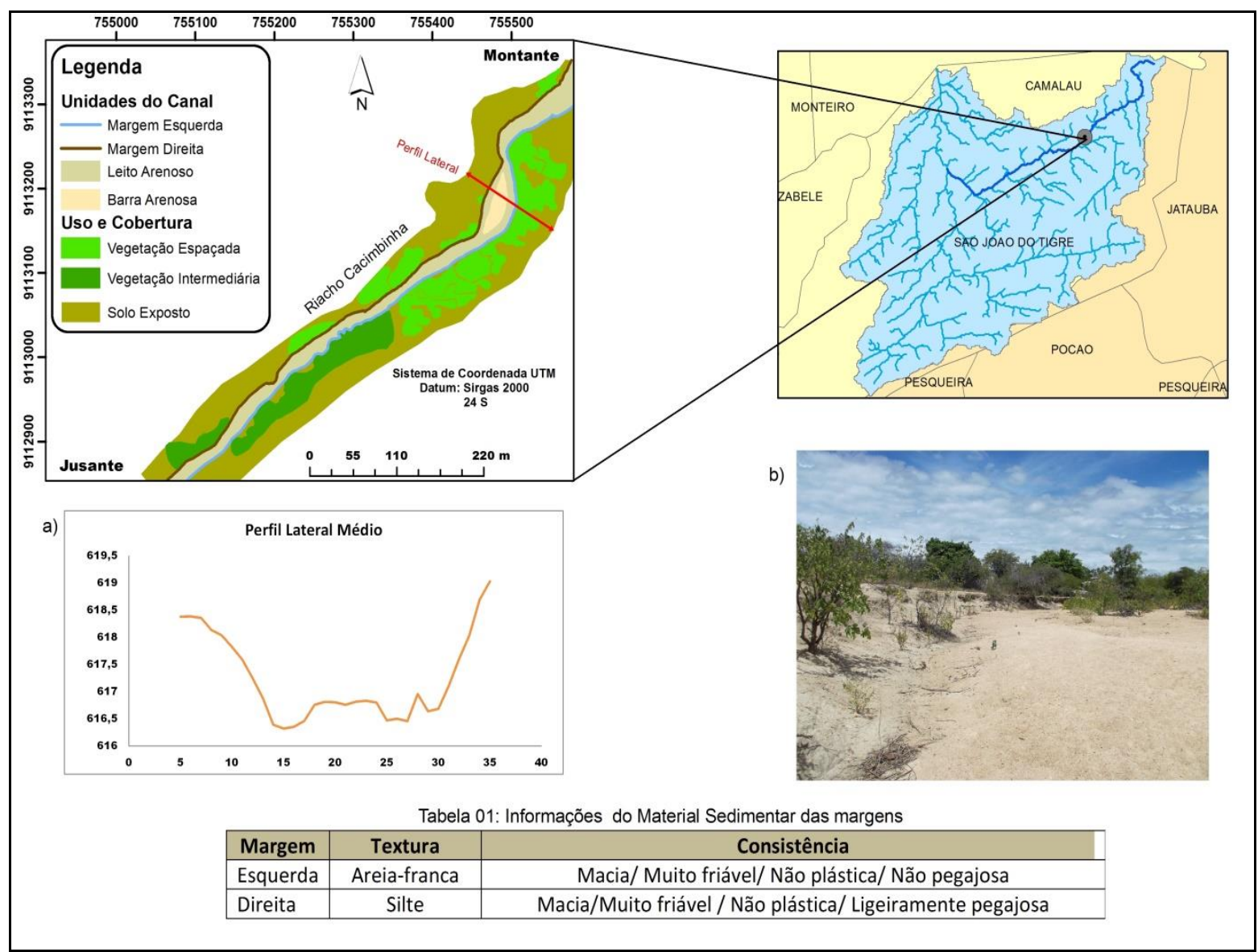

Fonte: Autores, 2016.

\section{Energia do fluxo e Estabilidade Lateral}

Após a classificação da resistência à erosão das margens, foi calculada a distribuição da energia do fluxo nos trechos analisados. Esse é um elemento essencial para avaliar o potencial de estabilidade das áreas, visto que o valor da energia do fluxo representa a força de distúrbio para o trecho, que interage com a resistência e determina a estabilidade lateral da área.

Então, a partir do modelo SWAT foi possível construir a tabela 02, que sumariza os dados encontrados para cada trecho, definindo a distribuição da energia do fluxo relacionado com a resistência lateral dos canais, que foram elencados para análise. Desse modo, os trechos que apresentam maior média de energia de fluxo foram os trechos 2,4 e 7 , apresentando respectivamente os valores de $99,59 \mathrm{~W} / \mathrm{m}, 74,95 \mathrm{~W} / \mathrm{m}$ e $38,75 \mathrm{~W} / \mathrm{m}$. Para a energia do fluxo especifico, os trechos 4 e 8 (tabela 02) destacam-se com um valor de $3,82 \mathrm{~W} / \mathrm{m}^{2}$ e $3,02 \mathrm{~W} / \mathrm{m}^{2}$, respectivamente,

Contudo, mesmo o trecho 4 não estando situado em uma localização do canal onde apresente um alto gradiente, foi identificado nesse trecho uma alta energia de fluxo especifica, pois trata-se de uma confluência, na qual o aumento da vazão relacionado à largura do canal vai gerar distúrbio. Para o trecho 7, que se localiza na cabeceira do riacho Cacimbinha, mesmo apresentando um dos gradientes mais altos entre os trechos analisados, foram identificadas baixas energias de fluxo total e especifica, devido à baixa vazão e a influência de uma barragem que está à jusante. 
Tabela 02 - Informações Hidrológicas dos trechos analisados.

\begin{tabular}{|c|c|c|c|c|c|c|c|}
\hline Trecho & $\begin{array}{c}\text { Área de } \\
\text { captação } \\
\left(\mathrm{km}^{2}\right)\end{array}$ & $\begin{array}{l}\text { Gradiente } \\
(\mathrm{m} / \mathrm{m})\end{array}$ & $\begin{array}{l}\text { Vazão } \\
\text { Média } \\
\left(\mathrm{m}^{3} / \mathrm{s}\right)\end{array}$ & $\begin{array}{c}\text { Vazão } \\
\text { Máxima } \\
\left(\mathrm{m}^{3} / \mathrm{s}\right)\end{array}$ & $\begin{array}{c}\text { Energia } \\
\text { Média } \\
(\mathrm{W} / \mathrm{m})\end{array}$ & $\begin{array}{c}\text { Energia } \\
\text { Máxima } \\
(\mathrm{W} / \mathrm{m})\end{array}$ & $\begin{array}{c}\text { Energia } \\
\text { Média E } \\
\left(\mathrm{W} / \mathrm{m}^{2}\right)\end{array}$ \\
\hline 1 & 531,59 & 0,0011 & 3,073 & 306,60 & 33,13 & 3305,15 & 0,41 \\
\hline 2 & 403,66 & 0,0040 & 2,541 & 224,00 & 99,59 & 8780,80 & 3,02 \\
\hline 3 & 218,49 & 0,0027 & 1,378 & 141,60 & 36,87 & 3788,37 & 2,17 \\
\hline 4 & 174,95 & 0,0061 & 1,248 & 116,40 & 74,95 & 6992,61 & 3,82 \\
\hline 5 & 143,09 & 0,0030 & 0,930 & 67,78 & 27,17 & 1979,45 & 1,13 \\
\hline 6 & 38,52 & 0,0131 & 0,225 & 27,98 & 28,87 & 3592,07 & 1,37 \\
\hline 7 & 8,21 & 0,0120 & 0,044 & 5,55 & 5,15 & 652,56 & 0,40 \\
\hline 8 & 36,09 & 0,0250 & 0,158 & 19,70 & 38,75 & 4826,50 & 3,05 \\
\hline
\end{tabular}

Fonte: Autores, 2016.

Tendo identificado a resistência das margens e avaliado a força de distúrbios para os trechos representativos, foi possível inter-relacionar essas informações e definir a estabilidade lateral para os trechos fluviais elencados para análise (tabela 3).

Sendo assim, com base nos resultados da energia do fluxo relacionados com a resistência das margens fluviais (tabela 03), os trechos 7 e 8 foram identificados como estáveis. Mesmo o trecho 8 apresentando um dos maiores índices de energia entre os trechos analisados, ele está classificado como estável, devido às margens exercerem controle estrutural.

Os trechos 1 e 5 foram identificados com estabilidade intermediária, pois os mesmos apresentam uma energia de fluxo que não é considerada alta em relação aos outros trechos analisados. Outro fator que também justifica a inserção deles nessa classificação é a presença da cobertura vegetal, pois de acordo com Pollen e Simon (2005) a cobertura vegetal, especialmente a parte radicular da vegetação, pode reforçar a resistência das margens, aumentando assim à resistência a erosão.

Tabela 03 - Relação da energia do fluxo com a resistência.

\begin{tabular}{c|c|c|c|c|c}
\hline Trecho & $\begin{array}{c}\text { Energia Média } \\
(\mathbf{W} / \mathbf{m})\end{array}$ & $\begin{array}{c}\text { Energia } \\
\text { Máxima } \\
(\mathbf{W} / \mathbf{m})\end{array}$ & $\begin{array}{c}\text { Energia } \\
\text { Média E. } \\
\left(\mathbf{W} / \mathbf{m}^{2}\right)\end{array}$ & Resistência & Estabilidade \\
\hline $\mathbf{1}$ & 33,13 & 3305,15 & 0,41 & Médio & Intermediário \\
\hline $\mathbf{2}$ & 99,59 & 8780,80 & 3,02 & Médio & Instável \\
\hline $\mathbf{3}$ & 36,87 & 3788,37 & 2,17 & Médio & Instável \\
\hline $\mathbf{4}$ & 74,95 & 6992,61 & 3,82 & Baixa & Instável \\
\hline $\mathbf{5}$ & 27,17 & 1979,45 & 1,13 & Médio & Intermediário \\
\hline $\mathbf{6}$ & 28,87 & 3592,07 & 1,37 & Baixa & Instável \\
\hline $\mathbf{7}$ & 5,15 & 652,56 & 0,40 & Alta & Estável \\
\hline $\mathbf{8}$ & 38,75 & 4826,50 & 3,05 & Alta & Estável \\
\hline
\end{tabular}

Fonte: Autores, 2016.

Ja para os trechos identificados como instáveis, tomou-se por base a relação da alta energia do fluxo com a baixa resistencia lateral dos canais. Nesse caso, destacaram-se os trechos 4 e 6 , que apresentaram maior índice de energia do fluxo, baixa resistência do material sedimentar que compõe

$\begin{array}{lllll}\text { Caminhos de Geografia } \quad \text { Uberlândia-MG } & \text { v. 21, n. } 75 & \text { Jun/2020 } & \text { p. 15-33 Página } 30\end{array}$ 
as margens e cobertura da vegetação escassa. Essas características justificam a classificação dos trechos como de baixa estabilidade lateral, isto é, são trechos instáveis. No caso dos trechos 2 e 3 , mesmo tendo uma média resistência, quando são relacionados à energia especifica, foram identificados como instáveis, principalmente o trecho 2, que apresenta áreas da planície de inundação antropizada.

\section{CONSIDERAÇÕES FINAIS}

Diante dos fatos apresentados, pode-se afirmar que a combinação dos processos fluviais da margem e leito, e a variabilidade dos materiais geram diferenciações da capacidade de ajustamento à morfologia do canal. Contudo, a estabilidade lateral do canal vai depender da resistência da capacidade de ajuste e da energia do fluxo, e da composição e disposição do material da margem, como na cobertura e uso das mesmas.

Ainda de acordo com os resultados obtidos, na aplicação metodológica foi possível identificar a estabilidade das margens e também entender que elas variam de acordo com as características endógenas de cada sistema fluvial. Outra conclusão foi que os processos de alterações laterais das margens fluviais estão entre os processos mais recorrentes nas paisagens fluviais e o entendimento do seu mecanismo de atuação é fundamental para a explicação da evolução dos diversos elementos da dinâmica fluvial, principalmente, dos ambientes fluviais do semiarido.

Ao mesmo tempo, o entendimento da relação dos materiais com a vegetação associada às margens no controle da resistência lateral indicou quais áreas são mais suscetíveis a erosão e, principalmente, quais áreas necessitam uma maior conservação da vegetação ripária devido à baixa resistência dos materiais das margens. Assim, a metodologia possibilita a identificação das áreas mais sensíveis à remoção da vegetação ripária.

No geral, diante do que foi explanado no presente trabalho, considera-se notória a necessidade de estudos mais detalhados para ambientes fluviais do semiárido, cuja identificação exerce uma importante função do ponto de vista hidrológico e ecológico aos ambientes fluviais do semiárido. Dessa forma, há uma contribuição tanto para identificar as áreas que apresentam modificação, como também para observar a resiliência do sistema fluvial, possibilitando com isso uma visão sistêmica e integrada dos componentes do ambiente fluvial, tendo como foco principal os recursos hídricos e gerenciamento dos mesmos.

\section{REFERÊNCIAS BIBLIOGRÁFICAS}

ACHARYA.K; GAUTAM.M. Evaluation of bendway weir bank stabilizationtechniques for stream restoration. Journal of River Basin Management, v.10:2, p. 171-176, 2012. https://doi.org/10.1080/15715124.2012.679737

ANDRADE, J.H.R. Dinâmica de margens em rios semiáridos: aplicações metodológicas no rio Jaguaribe - Ceará - Brasil. Dissertação de Mestrado, Programa de Pós-graduação em Ambiente, Tecnologia e Sociedade. UFERSA. Mossoró, RN, 2016.

ANDRADE, J.H.R.; CAVALCANTE, A. A. Processos erosivos marginais no Baixo Jaguaribe: Estudo de caso no rio Jaguaribe - Ceará - Brasil. Revista GEONORTE (Edição Especial), v.10, p.429-432, 2014.

BIGARELLA, J. J.; SUGUIO, K.; BECKER, R. D. Ambiente Fluvial: Ambientes de Sedimentação, sua interpretação e importância. 1a. ed. Curitiba: Editora da Universidade Federal do Paraná. Associação de Defesa e Educação Ambiental,1979.

BRIERLEY, G. J. e FRYIRS, K. A., Geomorphology and River Management: Applications of the River Styles Framework. Oxford: Blackwell Publications. 2005. https://doi.org/10.1002/9780470751367

CAVALCANTE, A.A; CUNHA, S. B. Dinâmica Fluvial no Semiárido e Gestão dos Recursos Hídricos: Enfoques sobre a Bacia do Jaguaribe - CE. IN: Potencialidades MEDEIROS.C.N; GOMES.D.D.M;

$\begin{array}{lllll}\text { Caminhos de Geografia } \quad \text { Uberlândia-MG } & \text { v. 21, n. } 75 \quad \text { Jun/2020 } & \text { p. 15-33 Página } 31\end{array}$


ALBUQUERQUE.E.L.S; Cruz .M.L.B.C. Os Recursos Hídricos do Ceará: Integração, Gestão e Potencialidades.Fortaleza: IPECE, 2011. 268 p.

CAVALCANTI. L.C.S; Cartografia de paisagens: fundamentos. São Paulo: Oficina texto, 2014.

CARVALHO NETO, J. G. Simulação Hidrossedimentológica da Bacia do Riacho dos Namorados Com o Modelo SWAT. Dissertação (Mestrado em Engenharia Civil e Ambiental) - Universidade Federal de Campina Grande, Campina Grande - PB. 2011.

CHRISTOFOLETTI, A. Geomorfologia fluvial. São Paulo: Editora Edgard Blucher, 1981.

CHRISTOFOLETTI, A. Modelagem de sistemas ambientais. São Paulo: Edgar Blüncher, 1999.

COELHO NETTO, A. L. Hidrologia de encosta na interface com a geomorfologia. In: GUERRA, A. J. T.; CUNHA, S. B. Geomorfologia: uma atualização de bases e conceitos. 3. ed. Rio de Janeiro: Bertrand Brasil, 1998. p. 93-148.

CORRÊA, A. C. de B.; TAVARES, B. de A. C.; MONTEIRO, K. de A.; CAVALCANTI, L. C. de S.; LIRA, D. R de. Megageomorfologia e morfoestrutura do Planalto da Borborema. Revista do Instituto Geológico, São Paulo, v. 31, p. 35-52, 2010. https://doi.org/10.5935/0100-929X.20100003

FERNANDEZ, O.V.Q. Mudanças no Canal Fluvial do rio Paraná e Processos Erosivos nas Margens: região de Porto Rico-PR. Dissertação de Mestrado, Programa de Pós-Graduação em Geociências. UNESP, Rio Claro, 1990.

FRYIRS, K. A. AND BRIERLEY, G. J. Geomorphic Analysis of River Systems: An Approach to Reading the Landscape, John Wiley \& Sons, Ltd, Chichester, UK. 2013. https://doi.org/10.1002/9781118305454

GRAF, W. L. Fluvial Process in Dryland Rivers. Caldwell: The Blackburn Press, 1988. https://doi.org/10.1007/978-3-642-83048-8

HOOKE J.M. Changes in River meanders: a review of techniques and results of analyses. Progress in Physical Geography, v.8, p 403-508, 1984. https://doi.org/10.1177/030913338400800401

HOOKE J.M. An Analysis of the Processes of River Bank Erosion. Journal of Hydrology, v.42 p.39-62, 1979. https://doi.org/10.1016/0022-1694(79)90005-2

IBGE. Coordenação de Recursos Naturais e Estudos Ambientais. Manual Técnico de Pedologia 2.ed. Rio de Janeiro, 2007.

IBGE - Instituto Brasileiro de Geografia e Estatística. Cidades / Paraíba. Disponível em :<http://cidades.ibge.gov.br/xtras/perfil.php?lang=\&codmun=251410\&search=||infogr\%E1 ficos:informa\%E7\%F5es-completas>. Acesso em: 30 mar. 2016

KNIGHTON.A.D. Changes in a Braided Reach. Geological Society of America Bulletin, v. 83, p. 38133822,1972. https://doi.org/10.1130/0016-7606(1972)83[3813:CIABR]2.0.CO;2

LANGBEIN, W.B; LEOPOLD, L. B. River channel bars and dunes' Theory of kinematic waves, U.S. Geol. Surv. Prof. Pap. 422-L, 1968. https://doi.org/10.3133/pp422L

MAGALHÃES H.E.S. Avaliação do estado de potencial erosão das margens de um curso de água. Aplicação a troços estuarinos de rios do norte de Portugal. Dissertação submetida para especialização em hidráulica. Faculdade de engenharia da universidade do Porto. 2010.

MALTCHIK, L. Ecologia de Rios Intermitentes Tropicais. Grupo Ecologia de Rios do Semi-Árido. Departamento de Sistemática e Ecologia, Universidade Federal da Paraíba, Paraíba. 2012.

MATTOS, S. H. V. L.; PEREZ FILHO, A. Complexidade e estabilidade em sistemas geomorfológicos: uma introdução ao tema. Revista Brasileira de Geomorfologia, v. 5 n.1, p. 11-18,2004.

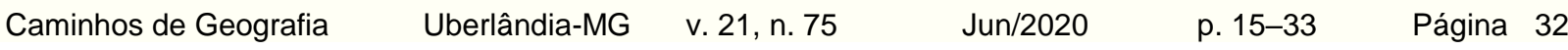


NANSON, G.C. and CROKE, J.C. A genetic classification of floodplains. Geomorphology v 4, p459486,1992. https://doi.org/10.1016/0169-555X(92)90039-Q

NANSON, G.C, HICKIN, E.J. A statistical analysis of bank erosion and channel migration in western Canada. Geological Society of America Bulletin v.97, p 497-504, 1986. https://doi.org/10.1130/00167606(1986)97<497:ASAOBE>2.0.CO;2

POLLEN.N; SIMON.A. Estimating the mechanical effects of riparian vegetation on stream bank stability using a fiber bundle model. Water Resources Research, v. 41, 2005. https://doi.org/10.1029/2004WR003801

RINALDI,M;MENGONI.B;LUPPI.L,DARBY.S.E; MOSSELMAN.E.Numerical simulation of hydrodynamics and bank erosion in a river bend. WaterResourcesResearch, v. 44, 2008. https://doi.org/10.1029/2008WR007008

ROCHA,P.C. Os processos geomórficos e o estado de equilíbrio fluvial no alto Rio Paraná, centro sul do Brasil.Geosul,v.24, n.48, 2009. https://doi.org/10.5007/2177-5230.2009v24n48p153

ROCHA,I.P; HOLANDA.F.S.R.H; FILHO.R.N.A; CASADO.A.P.BC; BANDEIRA.A.A. Meteorological and hydrological variables on occurrence of riverbank erosion along Lower São Francisco River.RevistaBrasileirade engenhariaagrícola v.17, n.2, p.137-144 , 2013. https://doi.org/10.1590/S1415-43662013000200004

SCHUMM, S. A. The fluvial system. Caldwell: The Blackburn Press, 1977.

SOUZA,J. O. P.; CORRÊA, A. C. B. Sistema fluvial e planejamento local no Semiárido. Mercator, v. 11, p. 149-168, 2012. https://doi.org/10.4215/RM2012.1124.0010

SOUZA. J.O.P. Dos Sistemas Ambientais ao Sistema Fluvial - Uma Revisão de Conceitos. Caminhos de Geografia Uberlândia v. 14, n. 46, p. 224-233, 2013.

SOUZA. J.O.P; ALMEIDA. J.D.M. Processos fluviais em terras secas: uma revisão. Revista OKARA: Geografia em debate v.9, p. 108-122, 2015.

STOTT,T. Natural recovery from accelerated forest ditch and stream bank erosion five years after harvesting of plantation forest on Plynlimon, mid Wales. Earth Surf.Process. Landforms30, 349-357, 2005. https://doi.org/10.1002/esp.1163

WOLMAN, M.G.; LEOPOLD, L.B. River Flood Plains: some observations of their formation. U.S. Geological Survey Professional Paper. 282-C, p.87-107, 1957. https://doi.org/10.3133/pp282C

Recebido em: 15/05/2018

Aceito para publicação em: 19/05/2020 